\title{
Brainstem cavernous malformations: the role of Gamma Knife surgery
}

\author{
Clinical article
}

\author{
Cheng-Chia Lee, M.D., ${ }^{1,2}$ David Hung-Chi Pan, M.D., ${ }^{1,2}$ Wen-Yuh Chung, M.D., ${ }^{1,2}$ \\ Kang-Du Liu, M.D., ${ }^{1,2}$ Huai-Che YANG, M.D., ${ }^{1,2}$ Hsiu-Mei Wu, M.D., ${ }^{1,3}$ \\ Wan-Yuo Guo, M.D., Ph.D., ${ }^{1,3}$ AND YANG-Hsin ShiH, M.D. 1,2
}

${ }^{1}$ Department of Neurosurgery, Neurological Institute, Taipei Veterans General Hospital; ${ }^{2}$ School of Medicine, National Yang-Ming University; and ${ }^{3}$ Department of Radiology, Taipei Veterans General Hospital, Taipei, Taiwan

\begin{abstract}
Object. The authors retrospectively reviewed the efficacy and safety of Gamma Knife surgery (GKS) in patients with brainstem cavernous malformations $(\mathrm{CMs})$. The $\mathrm{CMs}$ had bled repeatedly and placed the patients at high risk with respect to surgical intervention.

Methods. Between 1993 and 2010, 49 patients with symptomatic CMs were treated by GKS. The mean age in these patients was 37.8 years, and the predominant sex was female (59.2\%). All 49 patients experienced at least 2 instances of repeated bleeding before GKS; these hemorrhages caused neurological deficits including cranial nerve deficits, hemiparesis, hemisensory deficits, spasticity, chorea or athetosis, and consciousness disturbance.

Results. The mean size of the CMs at the time of GKS was $3.2 \mathrm{~cm}^{3}$ (range $0.1-14.6 \mathrm{~cm}^{3}$ ). The mean radiation dose directed to the lesion was $11 \mathrm{~Gy}$ with an isodose level at $60.0 \%$. The mean clinical and imaging follow-up time was 40.6 months (range 1.0-150.7 months). Forty-five patients participated in regularly scheduled follow-up. Twenty-nine patients $(59.2 \%)$ were followed up for $>2$ years, and $16(32.7 \%)$ were followed up for $<2$ years. The pre-GKS annual hemorrhage rate was 31.3\% (69 symptomatic hemorrhages during a total of 220.3 patient-years). After GKS, 3 episodes of symptomatic hemorrhage were observed within the first 2 years of follow-up (4.29\% annual hemorrhage rate), and 3 episodes of symptomatic hemorrhage were observed after the first 2 years of follow-up (3.64\% annual hemorrhage rate). In this study of 49 patients, symptomatic radiation-induced complications developed in only 2 patients $(4.1 \%$; cyst formation in 1 patient and perifocal edema with neurological deficits in the other patient). There were no deaths in this group.

Conclusions. Gamma Knife surgery is effective in reducing the rate of recurrent hemorrhage. In the authors' experience, it was possible to control bleeding using a low-dose treatment. In addition, there were few symptomatic radiation-induced complications. As a result, the authors believe that GKS is a good alternative treatment for brainstem CMs.

(http://thejns.org/doi/abs/10.3171/2012.8.GKS121066)
\end{abstract}

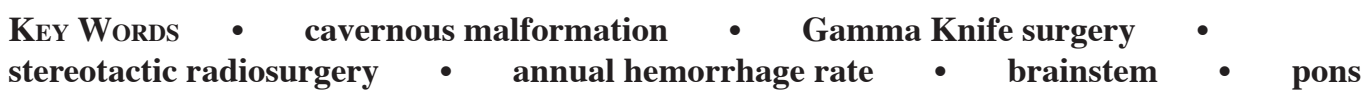

A LTHOUGH the optimal management of intracranial CMs is open resection, stereotactic radiosurgery has played an important role in treating these deeply seated and high-surgical-risk malformations throughout the past 20 years. In our previous report published in $2005,{ }^{16}$ we showed that the annual hemorrhage rate of intracranial CMs can be lowered from $29.2 \%$ to

Abbreviations used in this paper: $\mathrm{CM}=$ cavernous malformation; GKS = Gamma Knife surgery.
$10.3 \%$ (within 2 years) and to $3.3 \%$ (beyond 2 years) after GKS during a mean follow-up time of 5.4 years (range 9-123 months). Seizure control was achieved in $53 \%$ of patients with Engel Grade I or II, and there was no treatment-related death. Compared with patients with supratentorial CMs, the incidence of seizure was lower in patients with brainstem CMs, but we did observe a higher hemorrhage rate before treatment. ${ }^{16}$ For brainstem CMs, the goal of treatment is mainly aimed at controlling rebleeding and avoiding complications from repeated hem- 
orrhages, regardless of whether resection or radiosurgery is performed. From this point of view, GKS could be a good alternative treatment for patients with brainstem CMs. In this article, we present long-term treatment results in 49 patients with brainstem CMs, and we discuss post-GKS annual hemorrhage rates, radiation effects, and complications.

\section{Methods}

\section{Patient Population}

A consecutive series of 49 patients with 50 brainstem CMs underwent GKS between March 1993 and December 2010 . The mean age in these patients was 37.8 years (range 7.4-73.9 years), and the predominant sex was female (59.2\%). The location of the CMs varied: 34 lesions $(68.0 \%)$ were found in the pons, $10(20.0 \%)$ in the midbrain, $3(6.0 \%)$ in the pons-medulla oblongata junction, and $3(6.0 \%)$ in the medulla oblongata.

Before GKS, hemorrhage had occurred twice in 34 CMs (69.4\%), 3 times in $10 \mathrm{CMs}(20.4 \%)$, and 4 times in 5 lesions (10.2\%) (Table 1). In this study, episodes of hemorrhage were calculated based on the occurrence of newly developed neurological symptoms associated with MRI findings of recently developed hemorrhage. In other words, an episode of bleeding documented on cerebral images should be compatible with the timing of the patient's symptoms. In our cases, any asymptomatic hemorrhage, which was only found incidentally on follow-up MR images, was usually minimal and limited within the lesion. Asymptomatic hemorrhages often spontaneously regress and do not require intervention if they remain silent. Therefore, for a more objective comparison of the CM's status before and after treatment, we assessed the frequency of symptomatic hemorrhages.

Before treatment, various symptoms and signs cor-

\section{TABLE 1: Characteristics in 49 patients with 50 brainstem CMs treated with GKS between 1993 and 2010}

\begin{tabular}{lc}
\hline \multicolumn{1}{c}{ Characteristic } & No. $(\%)^{*}$ \\
\hline age in yrs (range) & $37.8(7.4-73.9)$ \\
F/M ratio (\% female) & $29: 20(59.2)$ \\
total no. of CMs & 50 \\
no. of CMs by location & \\
midbrain & $10(20.0)$ \\
pons & $34(68.0)$ \\
pons-medulla & $3(6)$ \\
medulla & $3(6)$ \\
no. of pre-GKS hemorrhagic events (\% of 118 total) & \\
2 & $34(69.4)$ \\
3 & $10(20.4)$ \\
4 & $5(10.2)$ \\
patients w/ pre-GKS neurological deficit & \\
yes & $49(100)$ \\
no & $0(0)$ \\
\hline
\end{tabular}

* Unless otherwise indicated. responding to hemorrhages were observed in the patients; these included cranial nerve deficits $(87.8 \%)$, hemiparesis $(77.6 \%)$, hemisensory deficits $(73.5 \%)$, spasticity $(53.1 \%)$, conscious disturbance $(12.2 \%)$, and chorea or athetosis (4.1\%) (Table 2).

\section{Gamma Knife Surgery}

Radiosurgery was performed using the Leksell Gamma Knife model C (Elekta AB). The mean lesion volume was $3.2 \mathrm{~cm}^{3}\left(0.1-14.6 \mathrm{~cm}^{3}\right)$. The prescribed dose was placed at an isodose level of $50-85 \%$, and the mean margin dose was 11.0 Gy (range 9-15 Gy). (Table 3) A higher margin dose (> 12.5 Gy) strategy was not generally applied because of the benign nature of the lesion and was only used in the early part of this study. To achieve a highly conformal dose distribution, multiple small shots were used to maximize the mean dose inside the lesion (range 11.6-18.6 Gy) and to minimize the radiation-related volume outside the target. Treatment for CMs was based on findings on T2-weighted MR images, and the targeted edge of the $\mathrm{CM}$ was considered to be the region within the T2 signal-defined hemosiderin ring on these images. Recently, we also introduced time-of-flight MR angiography to our dose plan to avoid overradiation of surrounding vessels. The margin dose administered in a patient whose lesion bulged into the tissue of the brainstem was lowered to less than $12 \mathrm{~Gy}$.

\section{Follow-Up Imaging and Clinical Evaluation}

After GKS, all of the patients underwent MRI studies and clinical evaluation at 6-month intervals. Forty-five patients $(91.8 \%)$ underwent regularly scheduled follow-up MRI examinations and were available for study. The mean follow-up time was 40.6 months (range 1-150.7 months). Twenty-nine patients participated in regularly scheduled follow-up for at least 2 years, and another 16 patients did so for less than 2 years. We carefully observed any clues of hemorrhage, including new foci of high signal intensity on T1-weighted MR images, volume expansion of irradiated lesions, and edematous changes revealed on T2-weighted MR images. Although not all hemorrhages produce symptoms and signs, we still recorded these data for further study.

\section{Results}

The efficacy of radiosurgery was assessed by observation of hemorrhage in all patients with CMs who underwent follow-up MRI examinations. Figure 1 demon-

\section{TABLE 2: Neurological deficits pre-GKS in 49 patients with brainstem CMs}

\begin{tabular}{lcc}
\hline \multicolumn{1}{c}{ Neurological Sign } & No. of Patients & Percentage (\%) \\
\hline cranial nerve deficits & 43 & 87.8 \\
hemiparesis & 38 & 77.6 \\
hemisensory deficits & 36 & 73.5 \\
spasticity & 26 & 53.1 \\
conscious disturbance & 6 & 12.2 \\
chorea or athetosis & 2 & 4.1 \\
\hline
\end{tabular}


TABLE 3: Gamma Knife surgery parameters for patients with brainstem CMs

\begin{tabular}{lcc}
\hline \multicolumn{1}{c}{ Parameter } & Mean & Range \\
\hline tumor vol $\left(\mathrm{cm}^{3}\right)$ & 3.2 & $0.1-14.6$ \\
margin dose $(\mathrm{Gy})$ & 11.0 & $9.0-15$ \\
max dose $(\mathrm{Gy})$ & 18.5 & $13.3-30$ \\
mean dose $(\mathrm{Gy})$ & 14.3 & $11.6-18.6$ \\
isodose level $(\%)$ & 60.0 & $50-85$ \\
no. of isocenters & 9.1 & $1-22$ \\
\hline
\end{tabular}

strates the case of 1 patient with previous bleeding who remained free from hemorrhage 163 months after GKS. Unlike this patient, some other patients experienced several episodes of bleeding, even after repeated GKS.

\section{Pre-GKS Hemorrhage Rate}

We calculated the pre-GKS hemorrhage rate in 49 patients who experienced $>2$ bleeding episodes. The preGKS observation period extended from the time of the patient's first symptomatic image-documented hemorrhage to the time of GKS. A total of 220.3 patient-years were recorded. There were 118 episodes of hemorrhage during this period. After exclusion of the first hemorrhage $(118-49=69$ episodes $)$, the calculated annual hemorrhage rate was $31.3 \%$ (69 episodes in 220.3 patient-years)

\section{Post-GKS Hemorrhage Rate}

An episode of hemorrhage was defined as any new or worsening neurological deficits accompanied by MRI- documented new bleeding. In other words, asymptomatic hemorrhage episodes whose only evidence was present on MRI were excluded. The posttreatment observation period extended from the time of treatment until any one of the following occurred: the most recent clinical or imaging follow-up, surgical intervention, or death from another cause. Therefore, the average post-GKS follow-up time was 40.6 months (range 1-150.7 months) with an overall observation period of 172.4 patient-years. Six episodes of hemorrhage in 6 patients were documented during this period (0.13 hemorrhage per patient). Three of these episodes occurred within 2 years after GKS, and 3 episodes occurred $>2$ years after GKS. The annual hemorrhage rate during the first 2 years after GKS was calculated to be $4.29 \%$ (3 hemorrhage episodes/70.0 patient-years), and the annual hemorrhage rate after the initial 2-year follow-up was calculated to be $3.64 \%$ (3 hemorrhage episodes $/ 82.4$ patient-years). A significant reduction $(\mathrm{p}<0.05)$ in the annual hemorrhage rate was demonstrated after GKS (31.3\% $\rightarrow 4.29 \% \rightarrow 3.64 \%$ ), as shown in Fig. 2 .

\section{Adverse Radiation Effects}

Two patients (4.1\%) exhibited new-onset neurological deterioration after GKS without a new hemorrhage. A cyst developed in 1 patient, and the other patient had permanent neurological deficits that were caused by adverse radiation effects and thus unrelated to hemorrhage. Three other patients $(6.1 \%)$ were discovered to have new $\mathrm{T} 2$ signal abnormalities surrounding their $\mathrm{CMs}$, but these patients were neurologically stable. Overall, the neurological status was either stable or improved in $95.9 \%$ of the patients after GKS.

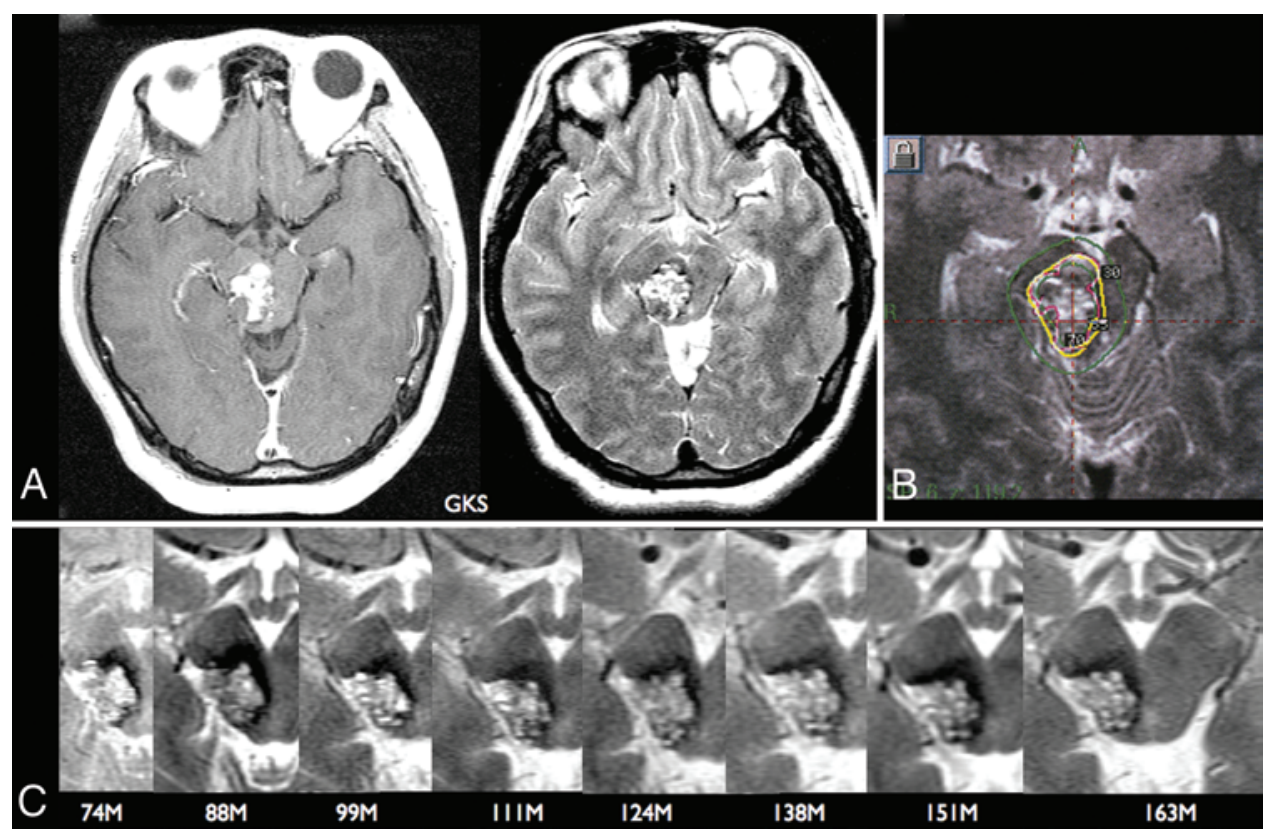

FIG. 1. Magnetic resonance images obtained in a 27-year-old woman who presented with a sudden-onset left limb weakness (muscle power Grade 4) and numbness, gait disturbance, diplopia, and facial numbness, which had lasted for 1 week. The MRI examination revealed a $3.2-\mathrm{cm}^{3} \mathrm{CM}$ in the midbrain with hemorrhage. A: T1-weighted and T2-weighted images revealing a recent hemorrhage in the right midbrain. A hemosiderin ring can be observed around the heterogeneous soft-tissue mass. B: Representative GKS planning for treatment of the brainstem CM with 10.6 Gy at a 55\% isodose level. C: Serial T2-weighted images demonstrating that the CM remains controlled up to 163 months $(\mathrm{M})$ of follow-up. 


\section{GKS for brainstem cavernous malformation}

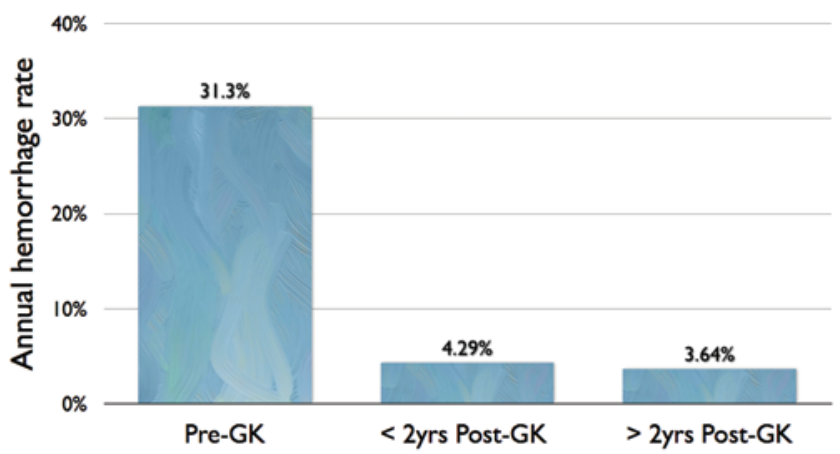

FIG. 2. Bar graph demonstrating changes in the annual hemorrhage rate following GKS (within 2 years and beyond 2 years). There was a decreasing trend in the hemorrhage rate after GKS. In most patients, hemorrhage was controlled, and the patient did not suffer any further neurological deterioration.

\section{Discussion}

Whether brainstem CMs are prone to bleeding or whether any bleeding is more likely to be symptomatic is debatable. ${ }^{6,22,24}$ The annual hemorrhage rates specifically associated with brainstem CMs ranged from $2.3 \%$ to $4.1 \%$ in studies of the natural history of the malformations, $2,13,18,22$ and from 2.7 to $6.8 \%$ before intervention in surgical series. ${ }^{5,6,9,20,22,25,26}$ After the first hemorrhage, however, CMs are destabilized and the risk of further bleeding is increased. The annual hemorrhage rate increases from $4.5 \%$ to $40 \% .^{1,11,12,14}$ Although some factors have been suspected to increase the rebleeding rate, there is no way to predict the behavior of brainstem CMs. Three treatment modalities are currently available for brainstem CMs: observation, resection by microsurgery, and radiosurgery. The selection of treatment modality is based mainly on the frequency of bleeding and the risk of surgery. In this paper, we have demonstrated the effects of radiosurgery on brainstem CMs and shown that GKS can be a safe alternative treatment for hemorrhage control.

In our 2005 review of patients with CMs that placed them at risk for surgery, ${ }^{16}$ the annual hemorrhage rate after GKS was $10.3 \%$ for the first 2 years and $3.3 \%$ thereafter. In the present series of patients with brainstem CMs, the annual hemorrhage rate after GKS was $4.29 \%$ for the first 2 years, and $3.64 \%$ thereafter. Adverse radiation effects were observed in $4.1 \%$ of patients. The data presented in this article are similar to those of our previous report in that they show a decrease in the annual hemorrhage rates of symptomatic intracranial CMs. With continual evolution of imaging quality, GKS hardware, dose prescription, and treatment planning, we believe that advanced GKS technological innovations will be able to improve the results of treatment for brainstem CMs and avoid radiation injuries.

Up to 2010, there were 5 reports of GKS used specifically in patients with brainstem CMs that placed them at high risk for surgery, and a total of 258 cases were reviewed $^{4,10,15,17,19}$ (Table 4). Most of the patients had experienced at least 2 prior clinically significant hemorrhagic events, and the annual hemorrhage rate before GKS ranged from $28.2 \%$ to $32.4 \%$. After GKS, the annual hemorrhage rate decreased year after year. Kida et al. ${ }^{10}$ reported that in their study the annual hemorrhage rate decreased to $9.5 \%$ within 1 year and to $4.7 \%$ within 2 years. Monaco et al. ${ }^{17}$ reported similar data: the rate decreased from $8.22 \%$ within 2 years to $1.37 \%$ beyond 2 years. Nagy et al. ${ }^{19}$ further stratified patients into 2 groups: low-risk patients (hemorrhage $<1$ episode) and high-risk patients (hemorrhage $>2$ episodes). In their high-risk group, the annual hemorrhage rate decreased from $15 \%$ within 2 years after GKS to $2.4 \%$ beyond 2 years after GKS. The results in the low-risk group were even better: from $5.1 \%$ within 2 years to $1.3 \%$ beyond 2 years after GKS. Radiosurgery-related morbidity rates ranged from $3.2 \%$ to $11.8 \%$, although Liscak $^{15}$ reported that $28 \%$ of patients with brainstem CMs experienced temporary disorders after GKS. No deaths have been noted in recent reports. ${ }^{10,15,19}$

For a comparison with the results of radiosurgery, 46 surgical series encompassing 745 brainstem CMs were reviewed. ${ }^{8}$ Complete resection could be achieved in up to $92 \%$ of CMs (684 lesions), but 30 of the remaining 61 CMs rebled, resulting in 4 deaths. Four of these lesions were considered "recurrences" after complete resection. ${ }^{8}$ The early postoperative morbidity rate was high, ranging from $29 \%$ to $67 \%$ in larger surgical series. Although most complications were transient and likely attributable to postoperative edema, manipulation, or changes in microcirculation, long-term clinical outcomes in the 45 series (683 patients) were such that $85 \%$ of patients had the same or an improved condition, $14 \%$ had a worsened condition, and $1.9 \%$ died of surgery-related causes. ${ }^{8}$ Some advances related to microsurgical technique, such as neuronavigation with diffusion tensor imaging and white matter tractography, ${ }^{3}$ the intraoperative endoscope ${ }^{25}$ and intraoperative monitoring and mapping ${ }^{23}$ may lead to continued improvement in the surgical success rate. For surgically accessible brainstem CMs, the rate of successful resection will increase along with improvements in technique and gains in the surgeon's experience.

The radiobiological effect of GKS on CMs is still uncertain, but gradual endothelial cell proliferation and hyalinization yielding luminal closure are the possible mechanisms. ${ }^{17}$ Gewirtz et al. ${ }^{7}$ and Nyáry and colleagues ${ }^{21}$ reviewed the histological characteristics of CM specimens from patients who had undergone radiotherapy or helium-ion radiosurgery before surgery. Their lesions demonstrated fibrinoid necrosis, endothelial cell destruction, and marked fibrosis in the connective tissue stroma. In addition, most vessels were only partially obliterated, because of the lack of an elastic lamina or a muscular layer, which prevents CMs from schlerosing closed like high-flow arteriovenous malformations. ${ }^{7}$ We hypothesized that radiosurgery induces focal inflammatory and postradiation changes with fibrosis of the connective tissue stroma, which in turn reduces the risk of hemorrhage from thin-walled, low-flow CMs. In other words, the reason why the annual hemorrhage rate of CMs decreases a while after GKS may be due to a delayed radiation change in the stroma and partial luminal closure of vascular channels.

In the past, the assessment of radiosurgical effects on brainstem CMs was limited because of poor-quality 
TABLE 4: Literature review: radiosurgical results for brainstem $\mathrm{CMs}^{*}$

\begin{tabular}{|c|c|c|c|c|c|c|c|}
\hline \multirow[b]{2}{*}{ Authors \& Year } & \multirow[b]{2}{*}{$\begin{array}{l}\text { No. of } \\
\text { Cases }\end{array}$} & \multirow[b]{2}{*}{$\begin{array}{c}\text { Margin } \\
\text { Dose (Gy) }\end{array}$} & \multicolumn{2}{|c|}{ Annual Hemorrhage Rate (\%) } & \multirow[b]{2}{*}{ FU } & \multirow[b]{2}{*}{$\begin{array}{l}\text { RS-Related Morbidity Rate } \\
\qquad(\%, A R E)\end{array}$} & \multirow[b]{2}{*}{$\begin{array}{l}\text { Mortality } \\
\text { Rate (\%) }\end{array}$} \\
\hline & & & Pre-GKS & Post-GKS & & & \\
\hline Liscák et al., 2000 & 26 & NA & 4 & 6.4 & 24 mos & 28 (temporary); 8 (permanent) & 8 \\
\hline Kida, 2009 & 63 & 13.4 & NA & $9.5(<1 \mathrm{yr}) \rightarrow 4.7(1-2 \mathrm{yr})$ & 55 mos & 3.2 & 6.4 \\
\hline present study & 49 & 11 & 31.3 & $4.29(<2 \mathrm{yr}) \rightarrow 3.64(>2 \mathrm{yr})$ & $40.6 \mathrm{mos}$ & 4.1 & 0 \\
\hline
\end{tabular}

* $\mathrm{ARE}=$ adverse radiation effect; FU = follow-up; NA = not available; $\mathrm{RS}$ = radiosurgery.

$\dagger$ high-risk group.

$\ddagger$ low-risk group.

cerebral imaging studies (pre-MRI period), excessive radiation doses (>15 Gy), and incomplete or overly large target coverage. However, with the evolution of cerebral imaging, better dose planning software, and optimal dose prescription, there are far fewer complications than before. Although the most optimal treatment for brainstem CMs is still microsurgery, GKS also plays an important role in the treatment of high-surgical-risk patients with repeated bleeding.

\section{Conclusions}

Based on our investigation of brainstem CMs in 49 patients, we summarize our findings as follows:

1. Gamma Knife surgery is effective in reducing the rate of recurrent hemorrhage in patients with brainstem CMs. In this study the annual hemorrhage rate decreased from $31.3 \%$ to $4.29 \%$ within 2 years and further decreased to $3.64 \%$ after 2 years.

2. In our experience, it is possible to control bleeding using a low-dose treatment. The optimal dose directed to the lesion margin is suggested to be around $11.0 \mathrm{~Gy}$, and the mean dose directed to the lesion as a whole should be adjusted to approximately 14-16 Gy.

3. Symptomatic radiation-induced complications developed in only 2 patients $(4.1 \%)$ and included cyst formation in 1 patient and perifocal edema with neurological deficits in the other.

Given the results of this study, we believe that GKS is a good alternative in the treatment of brainstem CMs.

\section{Disclosure}

The authors report no conflict of interest concerning the materials or methods used in this study or the findings specified in this paper.

Author contributions to the study and manuscript preparation include the following. Conception and design: Pan, Lee, Liu. Acquisition of data: Pan, Lee, Liu. Analysis and interpretation of data: Lee, Yang. Drafting the article: Lee, Yang. Critically revising the article: all authors. Reviewed submitted version of manuscript: all authors. Approved the final version of the manuscript on behalf of all authors: Pan. Statistical analysis: Pan, Lee, Chung, Guo. Administrative/technical/material support: Pan, Chung, Wu, Guo. Study supervision: Pan, Chung, Wu, Guo, Shih.

\section{References}

1. Aiba T, Tanaka R, Koike T, Kameyama S, Takeda N, Komata T: Natural history of intracranial cavernous malformations. J Neurosurg 83:56-59, 1995

2. Cantu C, Murillo-Bonilla L, Arauz A, Higuera J, Padilla J, Barinagarrementeria F: Predictive factors for intracerebral hemorrhage in patients with cavernous angiomas. Neurol Res 27:314-318, 2005

3. Chen X, Weigel D, Ganslandt O, Fahlbusch R, Buchfelder M, Nimsky C: Diffusion tensor-based fiber tracking and intraoperative neuronavigation for the resection of a brainstem cavernous angioma. Surg Neurol 68:285-291, 2007

4. Duma CM, Lunsford LD, Kondziolka D, Bissonette DJ, Somaza S, Flickinger JC: Radiosurgery for vascular malformations of the brain stem. Acta Neurochir Suppl (Wien) 58: 92-97, 1993

5. Ferroli P, Sinisi M, Franzini A, Giombini S, Solero CL, Broggi G: Brainstem cavernomas: long-term results of microsurgical resection in 52 patients. Neurosurgery 56:1203-1214, 2005

6. Fritschi JA, Reulen HJ, Spetzler RF, Zabramski JM: Cavernous malformations of the brain stem. A review of 139 cases. Acta Neurochir (Wien) 130:35-46, 1994

7. Gewirtz RJ, Steinberg GK, Crowley R, Levy RP: Pathological changes in surgically resected angiographically occult vascular malformations after radiation. Neurosurgery 42:738-743, 1998

8. Gross BA, Batjer HH, Awad IA, Bendok BR: Brainstem cavernous malformations. Neurosurgery 64:E805-8E18, 2009

9. Isamat F, Conesa G: Cavernous angiomas of the brain stem. Neurosurg Clin N Am 4:507-518, 1993

10. Kida Y: Radiosurgery for cavernous malformations in basal ganglia, thalamus and brainstem. Prog Neurol Surg 22:31-37, 2009

11. Kondziolka D, Flickinger JC, Lunsford LD: Radiosurgery for cavernous malformations. Prog Neurol Surg 20:220-230, 2007

12. Kondziolka D, Lunsford LD, Flickinger JC, Kestle JR: Reduction of hemorrhage risk after stereotactic radiosurgery for cavernous malformations. J Neurosurg 83:825-831, 1995

13. Kondziolka D, Lunsford LD, Kestle JR: The natural history of cerebral cavernous malformations. J Neurosurg 83:820-824, 1995

14. Kupersmith MJ, Kalish H, Epstein F, Yu G, Berenstein A, Woo H, et al: Natural history of brainstem cavernous malformations. Neurosurgery 48:47-54, 2001

15. Liscák R, Vladyka V, Simonová G, Vymazal J, Novotny J Jr: Gamma knife radiosurgery of the brain stem cavernomas. Minim Invasive Neurosurg 43:201-207, 2000 


\section{GKS for brainstem cavernous malformation}

16. Liu KD, Chung WY, Wu HM, Shiau CY, Wang LW, Guo WY, et al: Gamma knife surgery for cavernous hemangiomas: an analysis of 125 patients. J Neurosurg 102 Suppl:81-86, 2005

17. Monaco EA, Khan AA, Niranjan A, Kano H, Grandhi R, Kondziolka D, et al: Stereotactic radiosurgery for the treatment of symptomatic brainstem cavernous malformations. Neurosurg Focus 29(3):E11, 2010

18. Moriarity JL, Wetzel M, Clatterbuck RE, Javedan S, Sheppard JM, Hoenig-Rigamonti K, et al: The natural history of cavernous malformations: a prospective study of 68 patients. Neurosurgery 44:1166-1173, 1999

19. Nagy G, Razak A, Rowe JG, Hodgson TJ, Coley SC, Radatz MW, et al: Stereotactic radiosurgery for deep-seated cavernous malformations: a move toward more active, early intervention. Clinical article. J Neurosurg 113:691-699, 2010

20. Nataf F, Roux FX, Devaux B, Page P, Turak B, Dezamis E, et al: [Brainstem cavernomas: surgical experience at the $\mathrm{CH}$ Sainte-Anne general hospital.] Neurochirurgie 53:192-201, 2007 (Fr)

21. Nyáry I, Major O, Hanzély Z, Szeifert GT: Histopathological findings in a surgically resected thalamic cavernous hemangioma 1 year after $40-$ Gy irradiation. J Neurosurg 102 Suppl: 56-58, 2005

22. Porter RW, Detwiler PW, Spetzler RF, Lawton MT, Baskin JJ, Derksen PT, et al: Cavernous malformations of the brainstem: experience with 100 patients. J Neurosurg 90:50-58, 1999
23. Quinones-Hinojosa A, Lyon R, Du R, Lawton MT: Intraoperative motor mapping of the cerebral peduncle during resection of a midbrain cavernous malformation: technical case report. Neurosurgery 56 (2 Suppl):E439, 2005

24. Robinson JR, Awad IA, Little JR: Natural history of the cavernous angioma. J Neurosurg 75:709-714, 1991

25. Sandalcioglu IE, Wiedemayer H, Secer S, Asgari S, Stolke D: Surgical removal of brain stem cavernous malformations: surgical indications, technical considerations, and results. J Neurol Neurosurg Psychiatry 72:351-355, 2002

26. Wang CC, Liu A, Zhang JT, Sun B, Zhao YL: Surgical management of brain-stem cavernous malformations: report of 137 cases. Surg Neurol 59:444-454, 2003

Manuscript submitted May 31, 2012.

Accepted August 1, 2012.

This study was presented at the 16th International Leksell Gamma Knife Society Meeting, Sydney, Australia, March 25-29, 2012.

Please include this information when citing this paper: DOI: 10.3171/2012.8.GKS121066.

Address correspondence to: David Hung-Chi Pan, M.D., Department of Neurosurgery, Neurological Institute, Taipei Veterans General Hospital, 17F, No. 201, Shih-Pai Road, Sec. 2, Peitou, Taipei 11217, Taiwan, ROC.email: hcpan@vghtpe.gov.tw. 